\title{
A Framework for Building Safe and Effective School Environments: Positive Behavioral Interventions and Supports (PBIS) ${ }^{1}$
}

\author{
Robert H. Horner ${ }^{a}$, Manuel Monzalve Macaya ${ }^{b}$ \\ ${ }^{\text {a }}$ University of Oregon, U.S.A. \\ ${ }^{\mathrm{b}}$ Universidad Catolica Del Maule, Chile
}

Received 15th August 2018 / final version received 15th October 2018 /

/ accepted 17th October 2018

\begin{abstract}
Schools throughout the world strive to establish safe and effective learning environments. One consistent challenge is student aggression, acting-out, withdrawal, and insubordination. The historic response to student problem behavior has been punishment and remediation. Recently, more positive, proactive and comprehensive options have emerged. Positive Behavioral Interventions and Supports (PBIS) is one framework that links school-wide prevention efforts with tiered behavior support practices. The present paper summarizes the logic and core features of PBIS, the research literature supporting both the feasibility and effectiveness of PBIS, and lessons learned about implementation of PBIS across more than 26,000 schools in the United States. Discussion focuses on issues associated with cultural adaptation of these practices as PBIS is used outside the U.S., and across an array of social contexts.
\end{abstract}

Keywords: positive behavior support, implementation science, school discipline, cultural adaptation

The fundamental theme of this special issue is that schools are effective learning environments when they not only deliver high quality curricula through effective instruction, but also provide a safe, predictable, consistent and supportive social climate. In an ideal school, all students want to come to school, interact constructively with each other, view adults as supportive instructors and mentors, engage with passion in academic activities, and build

1 Development of this paper was supported by the Office of Special Education Programs U.S. Department of Education (H326S980003 and H326K120005). Opinions expressed herein are those of the authors and do not necessarily reflect the position of the U.S. Department of Education, and such endorsements should not be inferred. 
the academic and social competence needed to be successful adults. Problem behaviors such as aggression, non-compliance, threats, taunts, theft, social withdrawal, disengagement, and property destruction are barriers to an effective learning community. Problem behaviors interfere with the learning of the student performing those behaviors (Walker \& Gresham, 2014), often hinder the learning of others (Walker, Colvin, \& Ramsey, 1995), and function as one of the most common reasons given by staff for leaving the teaching profession (Allen, 2005; Graham et al., 2011).

Building safe and disciplined school environments is equally as important as selection and delivery of effective curricula and use of evidence-based instructional practices. Historically, schools have relied too often on either punishment of problem behavior, or removal of students who engage in problem behavior as strategies for minimizing the deleterious effects of problem behavior. These strategies have proven over time to be both ineffective and expensive (Belfield et al., 2015; Rumberger \& Losen, 2017). Alternatives, such as Positive Behavioral Interventions and Supports (PBIS), have emerged emphasizing investment in a whole school approach to establishing a positive learning community. Schools are encouraged to define their local social standards (i.e., expectations), actively teach those standards, consistently acknowledge appropriate behavior, and provide clear, consistent and quick instructional correction for behavioral errors. The PBIS approach is currently being implemented in over 26,000 schools in the United States, in addition to being adapted and applied in over 21 other countries (Kelm, McIntosh, \& Cooley, 2014; Sugai, 2018). In this paper we describe the core features of PBIS, the empirical research examining the impact of PBIS on student outcomes, and lessons learned about large-scale implementation and cultural adaptation of school-wide discipline practices.

\section{Positive Behavioral Interventions and Supports (PBIS)}

PBIS is typically described as a framework for selecting and implementing evidence-based practices within a multi-tiered continuum of behavioral supports that result in social, emotional and academic success for all students (Horner, Sugai, \& Fixsen, 2017). The term, "framework" is an important distinction in this definition. PBIS is not a curriculum, intervention, or manualized approach that can be purchased or adopted in a two-day workshop. Rather PBIS is built on a few key assumptions and a series of core features that provide a template for how those features are achieved in each 
school. Adoption of PBIS by a school typically requires one to three years, and active district support.

The key assumptions guiding PBIS are that (a) students learn how to behave (both how to behave well and how to behave poorly), and this means we need to teach positive behaviors and minimize the learning of problem behaviors, (b) effective schools not only teach positive behaviors, but regularly monitor and acknowledge those behaviors, (c) investing in prevention of problems will be more effective and efficient than waiting for problems to arise, and trying to then focus on remediation, (d) effective behavior support needs to occur at differing levels of support intensity (all students receive general support, some students receive more structured, and intensive teaching and feedback, and a few students will need highly individualized and focused assistance to succeed), (e) the organization of behavior support needs to occur across the whole school, and (f) effective behavior support "practices" will be used with fidelity and sustainability when linked to supportive organizational systems. Individual students, and individual classrooms will always be important, but a central key to behavior support is to consider the whole school as a learning community.

From these assumptions it is logical to focus on the core features of a school that will make that school behaviorally effective. Clearly defining core features of successful schools allows not only the ability for evaluation but the design of action plans for improved implementation. It has been helpful to use the multi-tiered system of support model (McIntosh \& Goodman, 2016; Sprick, Booher, \& Garrison, 2009) drawn from community health, and advocated by Walker et al. (1996) for use in education. This approach starts with a vision of each school providing basic behavior support for all the students (e.g., a commitment to equity), and a recognition that some students will need more intensive levels of support to be successful. A summary of the core features for each of the three tiers of support in PBIS is provided below.

Tier I: Universal Behavior Support. The goal of Tier I behavior supports is to establish the preventive foundation for a positive, school-wide social climate. Tier I is a proactive approach targeting support focused on all students in a school. The overall vision is to create a social climate that is predictable, consistent, positive and safe. Tier I supports are designed to improve the quality of interactions and relationships not only between students and staff but among students. The eight core features of Tier I PBIS are: 
1) Leadership Team: PBIS is implemented and sustained by a leadership team within each school, typically composed of three to seven members, including a principal (or administrator of the school), grade-level representation, and individuals with knowledge about behavior support practices. The leadership team coordinates professional development for the staff, monitors both fidelity and impact data, and guides both adoption and adaptation of PBIS practices to fit the local community culture and context.

2) 3-5 Positively Stated School-wide Behavioral Expectations: To build a predictable and consistent social culture the students, families and staff define a small number of core social values (e.g., be respectful, be responsible, try your best) that are expected from all students, and are actively taught at the beginning of each school year. These school-wide expectations apply to all people (adults, students, visitors) in all parts of the school at all times. At the beginning of each year, and often with booster events throughout the year, students are taught the expectations, and explicit instruction is used to ensure that they can tell the difference between expected and not-expected behavior. The key is that teaching behavioral expectations is proactive (occurs early in each academic year before students build patterns of problem behavior), and occurs for all students (so all students not only know the expectations, but know that everyone else knows the expectations). The process for teaching behavioral expectations is adjusted to fit the developmental level of the students: more adult-guided in elementary school, and more collaborative and peer-based in high school.

3) System to regularly acknowledge student appropriate behavior: Schools need to be positive social environments. This does not just mean reducing aversive interactions, but actively working to increase the number and form of positive recognition from adults to students, students to students and adults to adults. In schools using PBIS, students regularly receive behavior-specific recognition for appropriate behavior. A goal often set in successful schools is to create an environment in which students are acknowledged for appropriate behavior at least four to five times as often as they are corrected for behavioral errors. The way this is achieved is again adapted to the developmental level of the students and the culture of the school community. 
4) Instructional consequences for problem behavior: A major challenge for schools is defining how to respond to problem behavior. Earlier strategies have emphasized punishment and exclusion. The logical message was to make it unpleasant to engage in problem behavior, or to suspend or remove students who engage in repeated problem behavior. Direct use of aversive consequences has proven ineffective for most school-related problem behavior (Walker \& Gresham, 2014), and suspension and expulsion have proven short-term solutions with high long-term costs (Rumberger \& Losen, 2017). Within PBIS, consequences for problem behavior are organized to mimic traditional responses to academic mistakes: (a) interrupt the mistake early, (b) label the mistake, (c) define and prompt the positive, alternative behavior that is expected, and (d) organize the environment to prevent the problem behavior from being inadvertently rewarded (by peers or adults). If the mistake persists, then provide Tier II or Tier III supports that involve more intensive assessment, elevate the antecedent events to prevent mistakes, improve instruction on appropriate behavior, add recognition of appropriate behavior, and terminate any inadvertent reward for problem behavior.

5) Formal classroom management protocols: PBIS is a school-wide approach to student social behavior. A central part of this process, however, is attention to the features of effective classrooms. Each teacher has his/her own views of how their classroom should be managed, and these perceptions should be honored. At the same time, solid research now indicates that a small number of key classroom practices make a huge difference in both the social and academic success of students (Domitrovich et al., 2016; Farmer, Reinke, \& Brooks, 2014; Simonson et al., 2008; Simonson \& Meyers, 2015). The major theme from this research is that too often teachers over-emphasize the role of consequences to manage student behavior, and dramatically underestimate the importance of proactive and preventive efforts.

6) Collection and use of data for decision-making about behavior support: Among the most significant advances in education over the past two decades is the availability of information about student academic and social behavior. Never before has so much information been available at such a low cost. Unfortunately, most educational systems neither collect and organize their data well, nor provide personnel with the training 
to use data for efficient and effective decision-making (Newton et al., 2011). A central component of PBIS is the collection of data to address three iterative questions: (a) Are we doing the practices we have set out to do? (b) Are students benefiting (academically and socially)? and (c) What is the smallest change we can make that will have the largest positive impact for students? Schools using PBIS have highly efficient procedures for collecting, summarizing and using data (Horner et al., 2018).

7) Bully prevention procedures: A recent addition to the Tier I elements of PBIS is attention to bully prevention practices. Bullying involves the use of threats, verbal or physical aggression or other forms of intimidation. Bullying is typically a student-to-student problem, often unwitnessed by adults, and maintained by both access to physical reinforcers (e.g., money, food) and more often by social attention from bystanders and victims (Copeland et al., 2013). Bullying occurs at a much higher frequency than traditionally reported, and can undermine the social culture of a school (Christensen et al., 2012; Cook et al., 2010). Recent bully prevention efforts indicate high success when students are taught (a) a response to bullying behavior that eliminates social attention, and (b) an alternative social routine if someone indicates to you that you are engaging in bullying (Ross \& Horner, 2009). This has led to adding to PBIS Tier I core features the teaching of how students should respond when they are faced with (or witness) problem behavior performed by others. Students need a routine for responding to problem behavior that limits the attention and social recognition that too often maintains bulling behaviors. Teaching this routine proactively to all students makes a difference in the level of inadvertent reward for peer-maintained bulling behavior.

8) Family engagement: An often cited, but less-often actualized feature of effective schools is employment of practices that both inform and listen to input from families. Schools succeed best when educators, students and families each participate in shaping the social culture of the school. Establishing highly efficient and functional ways to both inform and listen to families is an emerging process in the field, and one we anticipate will have high value (Garbacz et al., 2018). 
Tier II: Targeted Behavior Support: A central assumption within PBIS is that an array of variables (i.e., prior learning history, academic failure, peerrecruited problem behavior) will result in Tier I supports being insufficient for some students. Historically, schools have not viewed behavior support on a continuum. Tier I supports were viewed more as family and community responsibility, and if a student persistently engaged in problem behavior they were classified as exceptional, and relegated to an alternative support track. Within PBIS, an efficient allocation of support resources leads to development of at least three levels of behavior support intensity. Tier I for all, Tier II for some who need only a little more support, and Tier III for the few students needing high intensity support. The most frequently missed step in this continuum is the availability of Tier II behavior supports. Tier II is conceptualized as a level of support that is highly efficient, quickly accessed, and a solid foundation if additional Tier III supports are needed. Examples of Tier II behavior supports include Check-in/Check-out (CICO; Maggin et al., 2015), First Step to Success (Walker et al., 1998), Social Skills Clubs (Elliott \& Gresham, 1991) and Academic Homework Clubs. The core features of Tier II supports are:

9) Coordinating school team: A small team (typically two to five people) led by a behavioral specialist is responsible for selection, support implementation and data collection and on-going evaluation.

10) High organizational efficiency: Tier II practices require small "extra" time and organizational resource. CICO, for example, requires an additional 10 hours of staff time per week to implement. Most Tier II practices are implemented similarly across students (in contrast with Tier III practices that are tailored to each student). This allows for efficiency and ease of implementation.

11) Rapid Access: Tier II supports are typically established as a regular part of the school support process, and are not developed or added only in response to student problems. As a result, students are able to be referred, selected and enter support quickly. A major goal of Tier II supports is to prevent the exacerbation of emerging problem behavior patterns.

12) Increased daily structure: Tier II supports typically provide a student with increased points in the day when behavioral concerns are reviewed and assessed. In older students this translates into formal training in self-regulation and self-monitoring, in younger students this 
often amounts to setting aside brief times each day to receive teacher feedback on behavior.

13) Increased instruction on and recognition of positive behaviors: The major way to change student behavior is to define, teach, monitor and reward desired behavior while placing problem behavior on extinction. Students with at-risk behavior often are in a position of receiving infrequent positive feedback. A central feature of Tier II supports is to increase instruction on behavioral expectations, and increase both the rate and the precision of behavior-specific positive feedback on a daily basis.

14) Improved timeliness and precision of behavioral corrections: The repetition of problem behaviors is typically associated with inadvertent positive consequences (obtaining rewarding results, or avoiding aversive events). A central focus of Tier II supports is to re-define problem behaviors as "not being examples of positive, behavioral expectations". The occurrence of problem behavior is quickly followed by (a) labeling the behavior as not appropriate, (b) clarifying the appropriate alternative, and (c) limiting the student's access to inadvertent reinforcing consequences.

Tier III: Intensive, Individualized Support: The third tier of PBIS targets those students with the most significant support needs. Often assumed to include three to five percent of any student-body, these are students with physiological, emotional and social challenges that require more complex and individualized intervention. Extensive research and program development has targeted the design of Tier III supports (Brown, Anderson, \& De Pry, 2015; Crone \& Horner, 2003; Walker, Colvin, \& Ramsey, 1995; Walker \& Gresham, 2014). Within the PBIS framework, Tier III supports include:

15) Individual student support teams: A central assumption behind the design of individualized supports is that the team of people who develop, implement and assess support are knowledgeable about the unique needs and preferences of the student (family), actively embedded in the local school context, and skilled professionals with training in behavioral and instructional practices. This means that in most cases the team building an individualized support plan will include a student (or representative), the teaching and support staff, an administrator, and a behavior support specialist. 
16) Individualized Assessment: Tier III supports are designed based on the specific learning and behavioral patterns of a student. As such formal assessment of academic skills, behavioral function, and mental health of the student serve as the foundation for support planning. The goal is to better understand the strengths a student brings to his/her classes as well as the sources of challenge within the school setting. At a minimum the assessment should identify the specific behaviors that are posing a barrier for the student, when and where those behaviors are most and least likely, what possible reinforcers are maintaining those behaviors, and any episodic events (motivating operations) that affect the likelihood of the problem behaviors.

17) Individual support plan: An individual Tier III support plan is expected to be focused not just on reduction of problem behavior, but development and support of the positive behaviors that will allow a student to be socially and academically successful. Individualized plans are comprehensive in their scope, emphasize the full school day (if not the full student day), and include practices to (a) prevent behavioral problems, (b) teach appropriate behavior, (c) place problem behavior on extinction, and (d) monitor and adapt to improvements and regressions over time.

18) Implementation of Tier III support: The development of an individualized support plan requires the design of an "action plan" for effective implementation. The plan may include special education supports, or additional educational accommodations that necessitate coordination and staffing. The important feature here is that there is not only a plan of support that describes how the student will be assisted, but an active plan defining the resources, scheduling and management needed to have that plan implemented with high integrity.

19) Elevated data collection and decision-making: Tier III supports are inherently complex, and adaptive. On at least a weekly basis staff should collect and summarize data indicating (a) if the plan is being implemented with integrity, and (b) if the support is having the desired effects on student behavior. Individualized support plans typically require more frequent and specific data collection than is used schoolwide (May et al., 2018). These data are used by school personnel to both assess if a support plan is being effective, and adapt the plan to match unique needs and opportunities. 
20) Elevated family engagement: The success of Tier III supports typically requires more than investment by school personnel. The student is viewed as a key leader in his/her own support, and the assistance received from the student's family is often a central asset.

\section{Empirical Support for PBIS}

Wide adoption of PBIS is fueled by documentation that schools are both able to implement these core features with integrity, and that PBIS adoption results in desirable outcomes for students, faculty and families. A central concern with any school-wide approach is the extent to which typical schools are able to use the approach as intended. Education is replete with examples of excellent ideas and practices that have proven too challenging to implement with a level of precision that results in student benefits. By contrast, the core features of PBIS have been found to build on existing school strengths and be adoptable with high fidelity (Barrett, Bradshaw, \& Lewis-Palmer, 2008; Horner et al., 2009; Kittelman et al., 2018; Mercer, McIntosh, \& Hoselton, 2017). More importantly, the PBIS core features are empirically associated with the following improvements for students and schools.

1) Reduction in problem behavior: Multiple randomized controlled trials have documented reduction in problem behavior and office discipline referrals when PBIS Tier I practices were implemented (Bradshaw, Mitchell, \& Leaf, 2010; Flannery et al., 2014; Horner et al., 2009; Kelm et al., 2014; McIntosh, Bennett, \& Price, 2011; Metzler et al., 2001; Nelson et al., 2002).

2) Improved prosocial behavior: PBIS is about more than reduction of problem behavior. Durable improvement in student behavior requires commitment to teaching positive social skills, and building a community that acknowledges and supports those positive behaviors. Systematic research has documented improved social competence and an elevated school-wide social climate following Tier I PBIS implementation (Metzler et al., 2001; McIntosh et al., 2011; Nelson et al., 2002). Bradshaw, Pas, Goldweber, Rosenberg and Leaf (2012) also found that the use of PBIS core features is associated with improved emotional regulation for students at risk for problem behavior. 
3) Improved academic achievement: School-wide behavior support does not directly improve academic outcomes, but when students are more likely to attend school, more likely to be academically engaged in class, and more likely to find the environment welcoming and comfortable they are also more likely to learn. At least four papers report improved academic outcomes associated with PBIS implementation (Horner et al., 2009; Kelm et al., 2014; Lassen, Steele, \& Sailor, 2006; Nelson et al., 2002).

4) Improved perception of school safety: Horner et al. (2009) assessed student and staff perception of school safety and found increases when PBIS was adopted. Similarly, Ross and Horner (2009) documented a 72\% reduction in bulling behaviors on the playground when elementary schools adopted Tier I PBIS core features.

5) Improved school organization: Schools adopting PBIS have also demonstrated improved organizational health and reduction in staff turnover (Bradshaw et al., 2008). The basic message is that adults in schools using PBIS find the environment more predictable, effective and desirable. In a recent study Ross, Endrulat and Horner (2011) found that teachers in schools using PBIS were more likely than teachers in nonPBIS schools to report that they were "effective" with their students.

This body of primary research is highly promising and approaching a level where both formal meta-analyses, and assessments across cultures will be appropriate and helpful.

\section{Implementation and Cultural Adaptation}

Our goals thus far have been to establish two key messages, (a) that the social behavior of students is a school-wide concern affecting student success (both academic and social success), and (b) that the multi-tiered set of core features associated with the PBIS approach is one viable and effective option for improving the social behavior of students and the social climate of schools. We turn now to the lessons learned about implementing the practices and systems of PBIS both within the United States and internationally. PBIS is currently used in over 26,000 schools in the U.S. and in school systems across 21 other countries. We have benefited from the emerging messages provided by the evolving field of "implementation science" (Fisher, Shortell, 
\& Savitz, 2016; Fixsen et al., 2005). Advocates of implementation science encourage separation of the content of a practice from the process by which it is adopted. Within education we look for practices that are documented to improve student outcomes, are practical for use in typical community and school settings, and are available at a reasonable cost. Too often, however, we assume that these solutions to academic and behavioral challenges can be implemented by purchasing "kits" or attending brief training events. Reality, and systematic measurement, suggest that implementation is a demanding process requiring attention to training, coaching, organizational systems, policy and the collection and use of data (Blase et al., 2015). The process of implementation is especially challenging when practices and systems are being extended beyond the cultural context where they were developed and tested. PBIS, for example, was developed in urban and suburban schools on the West Coast of the United States. Adoption of PBIS across the United States has required adaptations to meet cultural and contextual features of very small and very large schools, pre-schools and high schools, urban schools and rural schools, schools with very low cultural diversity, and schools with very high cultural diversity. The experience of extending multi-tiered behavior support across this range of contexts was expanded further when PBIS was introduced in different countries with not only different social norms, but significantly different political, fiscal and regulatory traditions for organizing education. From this experience we suggest that four main messages for large-scale implementation of educational practices have emerged.

\subsection{Focus on implementing core feature rather than "programs"}

Education is replete with packages and programs developed to improve academic and social outcomes. Nearly all of these include very well established practices, and the goal of the package is to make adoption more complete and efficient. Our experience is that packages and programs often work extremely well in some contexts (often those similar to the settings where the package was developed) but are more difficult to implement across the array of contexts needed for large-scale adoption. This has led us to organize PBIS as a "framework" of core features that can be accessed in many different ways. The basic message is that there are core features of schools that make them effective, but that these core features can be achieved through a variety of paths. In terms of behavior support we believe that any school attempting to support all students should provide that support across 
at least three different levels of intensity (multiple tiers), and invest initially in proactive (Tier I) efforts to define, teach, monitor and acknowledge a small set of well-defined, positive social expectations for everyone in the school. But the selection of these expectations will vary across cultures and contexts. Many schools, for example, select, "be respectful of others" as one basic expectation. But in some districts with a high gang presence, the word "respect" has taken on an alternate meaning, and fails to convey the message intended. In these contexts the school staff, students and families are likely to adopt a different expectation. Similarly, in some communities with a large proportion of Native American students there may be a long-standing tradition of honoring core tribal expectations, and these may be much more effectively extended to the school setting.

The key message is that while there are core features of effective educational environments (e.g., defining and teaching behavioral expectations for all) the specific path by which those features are implemented may be shaped by the strengths of the local setting and culture of the local community. The nuance of this approach involves being clear about the logic, form and function of the core feature so these elements are retained, while allowing high flexibility with respect to the steps taken to achieve the core features. Implementing educational practices with excessive reliance on packaged protocols will often prove an ill-fit as the package is applied across a wider array of contexts. Similarly implementing effective practices without clarity about and commitment to core features can result in implementation in name only, without benefit to students.

The implementation approach most effective for extending PBIS involves (a) development of a "blueprint" for PBIS adoption that lays out the core features of each tier of support, (b) providing examples of schools adopting these core features in different ways in different contexts, (c) monitoring the impact of implementation on student outcomes, and (d) specifying a formal process by which local leadership teams shape the path of adoption to fit the local values and culture (Sugai, Horner, \& Lewis, 2015).

\subsection{Implement effective practices in combination with supporting organizational systems}

Among the most consequential lessons we have learned is that effective practices (core features) are less likely to be adopted with precision, and 
unlikely to sustained over time (McIntosh \& Turri, 2014), unless they are paired with adoption of supporting organizational systems. Educational practices are the behaviors that adults perform to alter student skills and knowledge. Adults prompt, teach, acknowledge, correct, guide and nudge students with varying forms and frequencies to achieve improved student performance. Organizational systems are the features of the setting that affect the behavior of adults. Organizational systems are the policies, mission, operating protocols, teaming approach, hiring practices, evaluation criteria, and data systems that make it easier or more difficult to apply effective practices. Issues such as class size, time for academic preparation, opportunity for team meetings, inclusion of personnel with advanced technical knowledge, and the accuracy of and accessibility to student data are frequent challenges in schools today. Implementing effective practices without attention to the organizational systems needed for their adoption and nurturance is unlikely to lead to satisfactory outcomes.

The need to define and emphasize the role of organizational systems when implementing any educational innovation is especially important when implementation is considered on an international scale. Different countries not only vary in their levels of investment in education, but have very different standards and approaches for the role of teachers, building administrators, and related services personnel. Large scale implementation should include clarity and detailed steps for establishing the organizational systems needed for successful and sustained adoption.

Although there exists growing consensus among U.S. researchers concerning the critical role of organizational systems for implementation, and sustainability of effective practices, it is unclear how organizational systems are developed and prioritized in educational settings outside North America. For instance, although much is discussed about the insufficient funding for education in the U.S., other countries face even larger resource challenges. This is true in Chile, for example, which although generally ranked in the top three of South American countries in fiscal indicators, still faces major financial limits in education. These limitations have a negative effect on the implementation of organizational structures and processes that sustain effective practices.

An example of limited investment in organizational systems is the overreliance in Chile on external experts. When schools in Chile face an issue that 
cannot be solved with existing resources, the common response is to hire an external person to provide training and new strategies to address that specific problem. When the external expert leaves, schools are expected to sustain implementation of the strategy by themselves without any support. However, this approach to problem solving too often fails because the insufficient focus on organizational systems (e.g., resources, training, coaching) is inadequate to sustain any initial effects (McIntosh \& Turri, 2014).

Another critical organizational system that is not consistently established in Chilean school system is coaching capacity. Implementation science has demonstrated that training and professional development alone are seldom sufficient to ensure the effective adoption of a practice. Coaches within an educational context assist individuals to use skills and knowledge gained in the training sessions and help them understand how the use of these new skills helps improve student outcomes (Reinke et al., 2014). In addition, a coach might provide support in the implementation of their duties as a teacher; this support could include providing instruction, engaging in effective classroom management, or addressing the needs of a specific student. Besides developing skills toward fluency, coaching facilitates the processes of applying the skills and knowledge learned during training to the specific and unique needs of a school setting (Stormont \& Reinke, 2012). Therefore, it is important that individuals who carry out tasks as a coach possesses knowledge and experience with behavioral and PBIS expertise, school team implementation and problem solving. The ability of effective coaching to establish new educational skills, and adapt those skills to the local context makes investment in coaching a key component to cultural expansion of effective practices (Monzalve \& Horner, 2015).

\subsection{Use data to guide and improve implementation}

The foundation for any improvement in education lies in frequent and accurate measurement of the effects on student behavior. If an approach targets improvement in reading, writing or math performance then principled educators will regularly measure if student performance on these skills is improving. The same is true for social behavior. Regular review of the office discipline referrals (Irvin et al., 2004), attendance, and school climate is needed, possible, and becoming a core feature of effective schools (Horner et al., 2018). 
The use of student data to guide decisions is well documented, and becoming more common. It is less common to find school teams using "fidelity data" to guide implementation decisions. Fidelity refers to the extent to which educational practices are being used as intended. Latham (1992) and others have long lamented the iterative cycles of adopt-discard-adopt-discard, and attributed part of this problem to our tradition of not measuring if we are implementing with fidelity. As part of the process of adopting PBIS, schools (and districts) are encouraged to regularly (two to three times per years) assess if they are implementing the core features of Tier I, Tier II and/or Tier III supports. The Tiered Fidelity Inventory (TFI: Algozzine et al., 2014) is a fidelity measure that is used by local school teams to assess their adoption of PBIS. The TFI has been demonstrated to have high technical adequacy (McIntosh et al., 2017), and lead to action plans that directly assist schools to improve PBIS adoption over time. During the 2017-18 academic year, 14,990 schools in the United States measured the fidelity with which they were implementing PBIS, and over 9,750 of these schools documented that they were implementing with a sufficient level of Tier I fidelity to affect student outcomes.

The basic message is that regardless of the educational practice being considered, implementation should be guided by empirical measurement of fidelity. Fidelity measures should index the extent to which core features are in place, and should be assessed repeatedly within a year by those actively engaged in implementation. The results from fidelity measures should then be used for action planning that addresses continuous improvement and adaptation to on-going changes in the setting. Historically educators have collected data that was summarized and used primarily by administrators. The availability of inexpensive, accurate and timely data is transforming education. Local educators are now able to make decisions from practical data sources. A major question for the field is if this opportunity will be embraced, and if it will become more common for regular educators to ask two key questions from their data: (a) do fidelity data indicate that we are actually doing the practices we claim to do?, and (b) do these practices benefit students?

\subsection{Follow stages of implementation}

Adoption of effective educational practices can occur quickly for some smaller practices, but is more likely to consume two to four years for larger efforts 
(Bierman et al., 2002; Fixsen \& Blase, 2018). An important contribution from the implementation science literature is identification of four stages that typically guide adoption of new practices. Ignoring these stages often leads to school personnel launching training efforts too early, or shifting support for implementation away from a school before adequate fidelity has been achieved.

Stage 1 involves Exploration of a new practice. An adopting school, or school team, needs time to consider if a new approach or practice (e.g. PBIS) is needed in their school, is practical for their school, and can be adopted with available resources. The process of exploration often requires examining data to determine if a problem or deficit exists (Are students reading below expectation? Are student behaviors placing educational achievement at risk?), and consideration of whether the core features that research has shown to be most effective are (or are not) already in place. Blase, Kiser and Van Dyke (2013) have developed a Hexagon Tool for assisting schools, districts and state agencies to guide the discussions and data reviews needed for the exploration stage of implementation. Exploration ends with a team selecting core practices that they wish to implement.

Stage 2 involves establishing the Installation context to support effective implementation. During this stage the organizational systems such as teaming process, data access, policy development and resource commitment for effective implementation is assembled. The message within Stage 2 is to establish the context for successful adoption prior to launching major training efforts.

Stage 3 is Initial Implementation and is the stage at which direct training, coaching and support of personnel is delivered. Initial implementation includes the time from initial training until the educational practices are implemented with criterion level fidelity.

Stage 4 involves Scaling and Sustaining the practice. This stage involves activities designed to ensure that any educational practice be implemented with continued improvement processes, regular review, and on-going adaptation to changes in the cultural and organizational needs of the context. The variables needed to achieve initial implementation are often different from those needed for scaling and sustaining effective practices. 
The stages of implementation have been of special value in avoiding three common errors in the implementation process. The first error is to schedule and deliver staff training before the Exploration stage has been completed. If personnel are trained to do something they do not believe is necessary, contextual appropriate or effective, the training is unlikely to result in a positive effect. Taking the time to establish agreement about the need and value of a practice or system has dramatic impact on the likelihood of successful adoption.

The second error avoided through stage-guided implementation is to launch practices without the organizational systems needed for initial or sustained implementation. Training teams of school personnel to meet, use data and make decisions is a wonderful way to ensure that local culture and values will guide implementation. But if the training occurs and the teams do not have scheduled time to meet, the teams do not have access to the data they have been taught to use, or the teams lack the authority to act on their decisions, then the training will have little impact. Installing the core systems needed for successful implementation is a critical, if oft-missed, stage of implementation.

The third common implementation error is to withdraw attention and support from the implementation process after a school or district demonstrates minimally acceptable Tier I implementation. Too often the assumption is that if a school is able to implement initial fidelity with Tier I practices then they should have all they need for sustained and elaborated implementation of Tier II and Tier III practices. The stages of implementation teach us that what is needed for initial adoption is seldom sufficient for sustained, elaborated and/or scaled adoption. Implementing PBIS at Tier II and Tier III requires investment in personnel with behavior support expertise, and sustained implementation requires investment in organizational systems with ongoing review of fidelity and impact data by local teams (Horner, Sugai, \& Fixsen, 2017).

\section{Summary}

Any society formed around democracy, or a democratic republic, has an obligation to invest in the education of all children. As such the identification of effective educational practices is a high social objective. We argue here that part of any effective educational effort will be proactive and sustained 
attention to the social competence of students. This means more than teaching social skills, but establishing schools as learning communities with predictable, consistent, positive and safe social cultures.

The core features needed for building positive, school-wide social cultures are becoming well documented. These features are organized in the PBIS framework into a multi-tiered set of practices, systems and data-use protocols that have been demonstrated to be both practical for schools, and helpful to students. The challenge today is less to identify what is needed to make schools effective learning environments, and more about understanding the political, fiscal, and organizational variables that affect adoption of effective practices with high fidelity, sustainability, and scalability.

\section{References}

Algozzine, R. F., Barrett, S., Eber, L., George, H., Horner, R. H., Lewis, T. J., ... Sugai, G. (2014). SWPBIS Tiered Fidelity Inventory. Eugene, OR: OSEP Technical Assistance Center on Positive Behavioral Interventions and Supports. Retrieved from www.pbis.org

Allen, M. B. (2005). Eight questions on teacher recruitment and retention: What does the research say? Education Commission of the States. Retrieved from http://files.eric.ed.gov.fulltext/ ED489332

Barrett, S., Bradshaw, C., \& Lewis-Palmer, T. (2008). Maryland statewide PBIS initiative: Systems, evaluation, and next steps. Journal of Positive Behavior Interventions, 10, 105-114.

Belfield, C., Bowden, A. B., Klapp, A., Levin, H. M., Shand, R., \& Zander, S. (2015). The economic value of social and emotional learning. Monograph. New York: Center for Benefit-Cost Studies in Education Teachers College, Columbia University. Retrieved from http://cbcse. org/wordpress/wp-content/uploads/2015/02/SEL-Revised.pdf.Google Scholar

Bierman, K. L., Coie, J. D., Dodge, K. A., Greenberg, M. T., Lochman, J. E., McMahon, R. J., \& Pinderhughes, E. (2002). The implementation of the Fast Track Program: An example of a large-scale prevention science efficacy trial. Journal of Abnormal Child Psychology, 30, 1-17.

Blase, K. A., Fixsen, D. L., Sims, B. J., \& Ward, C. S. (2015). Implementation science: Changing hearts, minds, behavior, and systems to improve educational outcomes. Paper presented at the Wing Institute's Ninth Annual Summit on Evidence-based Education, Berkeley, CA. Retrieved from http://nirn.fpg.unc.edu/resources/implementation-science-changing-hearts-mindsbehavior and-systems-to-improve

Blase, K., Kiser, L., \& Van Dyke, M. (2013). The Hexagon Tool: Exploring context. Chapel Hill: National Implementation Research Network, FPG Child Development Institute, University of North Carolina at Chapel Hill.

Bradshaw, C., Koth, C., Bevans, K., Ialongo, N., \& Leaf, P. (2008). The impact of school-wide positive behavioral interventions and supports (PBIS) on the organizational health of elementary schools. School Psychology Quarterly, 23, 462-473. 
Bradshaw, C. P., Mitchell, M. M., \& Leaf, P. J. (2010). Examining the effects of schoolwide positive behavioral interventions and supports on student outcomes: Results from a randomized controlled effectiveness trial in elementary schools. Journal of Positive Behavior Interventions, 12, 133-148.

Bradshaw, C. P., Pas, E. T., Goldweber, A., Rosenberg, M. S., \& Leaf, P. J. (2012). Integrating school wide positive behavioral interventions and supports with tier 2 coaching to student support teams: The PBISplus model. Advances in School Mental Health Promotion, 5, 177-193.

Brown, F., Anderson, J., \& De Pry, R. (2015). Individual positive behavior supports: A standards based guide to supports in school and community settings. Baltimore: Paul H. Brookes Publishing.

Christensen, L. L., Fraynt, R. J., Neece, C. L., \& Baker, B. L. (2012). Bullying adolescents with intellectual disability. Journal of Mental Health Research in Intellectual Disabilities, 5, 49-65.

Cook, C. R., Williams, K. R., Guerra, N. G., \& Kim, T. E. (2010). Variability in the prevalence of bullying and victimization. In S. R. Jimerson, S. M., Swearer, \& D. L. Espelage (Eds.), Handbook of bullying in schools: An international perspective (pp. 347-362). New York: Routledge.

Copeland, W. E., Wolke, D., Angold, A., \& Costello, E. J. (2013). Adult psychiatric outcomes of bullying and being bullied by peers in childhood and adolescence. Journal of the American Medical Association Psychiatry, 70, 419-426.

Crone, D. A., \& Horner, R. H. (2003). Building positive behavior support systems in schools: Functional behavioral assessment. New York: Guilford Press.

Domitrovich, C. E., Bradshaw, C. P., Berg, J. K., Pas, E. T., Becker, K. D., Musci, R., ... Ialongo, N. (2016). How do school-based prevention programs impact teachers? Findings from a randomized trial of an integrated classroom management and social-emotional program. Prevention Science, 17, 325-337.

Elliott, S. N., \& Gresham, F. M. (Eds.) (1991). Social skills intervention guide. Circle Pines: American Guidance Service.

Farmer, T. W., Reinke, W. M., \& Brooks, D. S. (2014). Managing classrooms and challenging behavior: Theoretical considerations and critical issues. Journal of Emotional and Behavioral Disorders, 22, 67-73.

Fisher, E., Shortell, S., \& Savitz, S. (2016). Implementation science: A potential catalyst for delivery system reform. Journal of the American Medical Association, 315, 339-340.

Fixsen, D. L., \& Blase, K. A. (2018). The teaching-family model: The first 50 years. Perspectives on Behavior Science, 1-23.

Fixsen, D. L., Naoom, S. F., Blasé, K. A., Friedman, R. M., \& Wallace, F. (2005). Implementation research: A synthesis of the literature. Tampa, FL: University of South Florida, Louis de la Parte Florida Mental Health Institute, The National Implementation Research Network. Retrieved from http://nirn.fmhi.usf.edu/resources/detail.cfm?resourceid=31

Flannery, K. B., Fenning, P., McGrath Kato, M. M., \& McIntosh, K. (2014). Effects of school-wide positive behavioral interventions and supports and fidelity of implementation on problem behavior in high schools. School Psychology Quarterly, 29, 111-124.

Garbacz, S. A., McIntosh, K., Vatland, C. H., Minch, D. R., \& Eagle, J. W. (2018). Identifying and examining school approaches to family engagement within schoolwide positive behavioral interventions and supports. Journal of Positive Behavioral Interventions, 20, 127-137. 
Graham, S., Parmer, R., Chambers, L., Tourkin, S., \& Lyter, D. (2011). Documentation for the 2008-09 Teacher Follow-up Survey (NCES 2011-304). Washington, DC: U.S. Department of Education, National Center for Education Statistics.

Horner, R. H., Newton, J. S., Todd, A. W., Algozzine, B., Algozzine, K., Cusumano, D., \& Preston, A. (2018). A randomized waitlist controlled analysis of team-initiated problem solving professional development and use. Behavioral Disorders, 43, 444-456.

Horner, R. H., Sugai, G., \& Fixsen, D. L. (2017). Implementing effective educational practices at scales of social importance. Clinical Child and Family Psychology Review, 20, 25-35.

Horner, R. H., Sugai, G., Smolkowski, K., Eber, L., Nakasato, J., Todd, A., \& Esperanza, J. (2009). A randomized, waitlist-controlled effectiveness trial assessing school-wide positive behavior support in elementary schools. Journal of Positive Behavior Interventions, 11, 133-144.

Irvin, L., Tobin, T., Sprague, J., Sugai, G., \& Vincent, C. (2004). Validity of office discipline referral measures as indices of school-wide behavioral status and effects of school-wide behavioral interventions. Journal of Positive Behavior Interventions, 6, 131-147.

Kelm, J. L., McIntosh, K., \& Cooley, S. (2014). Effects of implementing school-wide positive behavioural interventions and supports on problem behaviour and academic achievement in a Canadian elementary school. Canadian Journal of School Psychology, 29, 195-212.

Kittelman, A., Eliason, B. M., Dickey, C. R., \& McIntosh, K. (2018). How are schools using the SWPBIS tiered fidelity inventory (TFI)? OSEP Technical Center on Positive Behavioral Interventions and Support. Retrieved from www.pbis.org

Lassen, S., Steele, M., \& Sailor, W. (2006). The relationship of school-wide positive behavior support to academic achievement in an urban middle school. Psychology in Schools, 43, 701-712.

Latham, G. (1992). Interacting with at-risk children: The positive position. Principal, 72, 26-30.

Maggin, D. M., Zurheide, J., Pickett, K. C., \& Baillie, S. J. (2015). A systematic evidence review of the check-in/check-out program for reducing student challenging behaviors. Journal of Positive Behavior Interventions, 17, 197-208.

May, S., Talmadge, N., Todd, A. W., Horner, R. H., McGovern, S., Morris, J.,...Cave, M. (2018). Individual SWIS 6.3.0 b20. Eugene: University of Oregon.

McIntosh, K., Bennett, J. L., \& Price, K. (2011). Evaluation of social and academic effects of school wide positive behaviour support in a Canadian school district. Exceptionality Education International, 21, 46-60.

McIntosh, K., \& Goodman, S. (Eds.). (2016). Integrated multi-tiered systems of support: Blending RTI and PBIS. New York: The Guilford Press.

McIntosh, K., Massar, M. M., Algozzine, R. F., George, H. P., Horner, R. H., Lewis, T. J., \& Swain Bradway, J. (2017). Technical adequacy of the SWPBIS tiered fidelity inventory. Journal of Positive Behavior Interventions, 19, 3-13.

McIntosh, K., \& Turri, M. G. (2014). Positive behavior support: Sustainability and continuous regeneration. In C. R. Reynolds, K. J. Vannest, \& E. Fletcher-Janzen (Eds.), Encyclopedia of special education: A reference for the education of children, adolescents, and adults with disabilities and other exceptional individuals (pp. 2061-2064). Hoboken: Wiley.

Mercer, S. H., McIntosh, K., \& Hoselton, R. (2017). Comparability of fidelity measures for assessing Tier 1 school-wide positive behavioral interventions and supports. Journal of Positive Behavior Interventions, 19, 195-204. 
Metzler, C. W., Biglan, A., Rusby, J. C., \& Sprague, J. R. (2001). Evaluation of a comprehensive behavior management program to improve school-wide positive behavior support. Education and Treatment of Children, 24, 448-479.

Monzalve, M., \& Horner, R. H. (2015). An examination of classroom management training in K-12 teachers and administrators in the Maule region of Central Chile. International Journal of Positive Behavioural Support, 5, 16-24.

Nelson, J. R., Benner, G. J., Reid, R. C., Epstein, M. H., \& Currin, D. (2002). The convergent validity of office discipline referrals with the CBCL-TRF. Journal of Emotional and Behavioral Disorders, 10, 181-188.

Newton, J. S., Algozzine, B., Algozzine, K., Horner, R. H., \& Todd, A. W. (2011). Building local capacity for training and coaching data-based problem solving with positive behavior intervention and support teams. Journal of Applied School Psychology, 27, 228-245.

Reinke, W. M., Stormont, M., Herman, K. C., Wang, Z., Newcomer, L., \& King, K. (2014). Use of coaching and behavior support planning for students with disruptive behavior within a universal classroom management program. Journal of Emotional and Behavioral Disorders, 22(2), 74-82.

Ross, S. W., Endrulat, N. R., \& Horner, R. H. (2011). Adult outcomes of school-wide positive behavior support. Journal of Positive Behavioral Interventions, 13, 1-12.

Ross, S. W., \& Horner, R. H. (2009). Bully prevention in positive behavior support. Journal of Applied Behavior Analysis, 42, 747-759.

Rumberger, R. W., \& Losen, D. J. (2017). The hidden costs of California's harsh school discipline: And the localized economic benefits from suspending fewer high school students. Los Angeles: The Center for Civil Rights Remedies at the Civil Rights Project of the University of California at Los Angeles.

Simonsen, B., Fairbanks, S., Briesch, A., Myers, D., \& Sugai, G. (2008). Evidence-based practices in classroom management: Considerations for research to practice. Education and Treatment of Children, 31, 351-380.

Simonsen, B., \& Myers, D. (2015). Classwide positive behavior interventions and supports. New York: The Guilford Press.

Sprick, R., Booher, M., \& Garrison, M. (2009). Behavioral response to intervention: Creating a continuum of problem-solving and support. Eugene: Pacific Northwest Publishing.

Stormont, M., \& Reinke, W. M. (2012). Using coaching to improve classroom implementation fidelity within school-wide positive behavior support systems. Beyond Behavior, 21, 11-19.

Sugai, G. (May 2018). Getting Started with PBIS. Presentation delivered at the Northeast PBIS Forum, Mystic, CT.

Sugai, G., Horner, R. H., \& Lewis, T. (2015). Behavioral interventions and supports implementation blueprint. Retrieved from www.pbis.org

Walker, H. M., Colvin, G., \& Ramsey, E. (1995). Antisocial behavior in schools: Strategies and best practices. Pacific Grove: Brooks/Cole.

Walker, H. M., \& Gresham, F. M. (Eds.) (2014). Handbook of evidence-based practices for emotional and behavioral disorders: Applications in schools. New York: The Guilford Press.

Walker, H. M., Horner, R. H., Sugai, G., Bullis, M., Sprague, J. R., Bricker, D., \& Kaufman, M. H. (1996). Integrated approaches to preventing antisocial behavior patterns among school-age children and youth. Journal of Emotional and Behavioral Disorders, 4, 194-209. 
Walker, H. M., Kavanagh, K., Stiller, B., Golly, A., Severson, H., \& Feil, E. (1998). First Step to Success. An early intervention approach for preventing school antisocial behavior. Journal of Emotional and Behavioral Disorders, 6, 66-80.

\section{Authors}

Robert H. Horner, Ph.D., Special Education, 1235 University of Oregon, Eugene, OR. 97405, e-mail: robh@uoregon.edu

Manual Monzalve Macaya, Ph.D., Special Education, Universidad Catolica Del Maule, Chile, e-mail: mmonzalve@ucm.cl

\section{Rámec pro budování bezpečného a efektivního prostředí ve škole: Pozitivní intervence a podpora chování (PBIS)}

Abstrakt: Školy po celém světě se snaží vytvářet bezpečné a efektivní učební prostředí. Neustálou výzvou je agrese studentů, jejich nekázeň a absence. Tradičním přístupem $\mathrm{k}$ problémovému chování byl trest a náprava. $\mathrm{V}$ poslední době se ale objevují možnosti charakteristické pozitivním, proaktivním a komplexním přístupem. Pozitivní intervence a podpora chování (Positive Behavioral Interventions and Support; PBIS) je jedním z možných rámců, které spojují celoškolní preventivní přístup a víceúrovňovou podporu chování. Tato studie shrnuje logiku a základní znaky PBIS, výzkumnou literaturu týkající se realizovatelnosti a efektivnosti PBIS a také poznatky z implementace PBIS na více než 26000 školách v USA. Diskuse se pak soustředí na problémy spojené $\mathrm{s}$ adaptací programu $\mathrm{v}$ odlišném kulturním prostředí mimo USA a v různých sociálních kontextech.

Klíčová slova: pozitivní podpora chování, implementace, školní kázeň, kulturní adaptace 